\title{
Trazados y configuraciones espaciales: tras la huella del patrimonio urbano en Quibdó, Colombia ${ }^{2}$
}

- Recepción: 10 de abril de 2020 - Evaluación: 18 de junio de 2021 - Aprobación: 21 de junio de 2021

\begin{abstract}
Resumen: En el artículo se hace una reflexión acerca de la conformación del trazado urbano de la ciudad de Quibdó, en el Pacífico colombiano, en relación con las configuraciones espaciales que lo constituyen y que este conforma. Esta apuesta entiende la conformación del trazado y los espacios en correlación con diversas relaciones sociales, en los conocimientos, los entendimientos, las apropiaciones y las vivencias de los grupos locales, así como en las relaciones de los pobladores con el entorno físico y natural, como tejidos de relaciones y dinámicas constructoras de espacio y territorio. A partir de las pesquisas realizadas en la estructura urbana de Quibdó, se identifican configuraciones espaciales y trazados característicos de la ciudad a través de los cuales se rastrean comprensiones, identidades y formas de pensamiento y de organización asociadas al espacio. Las indagaciones suscitan la detección de elementos de valor asociados a las espacialidades y trazados que permiten vislumbrar elementos patrimoniales vinculados a lo urbano. Se trata de una apuesta por entender otras formas de aproximación que pongan en tensión la mirada hegemónica que cataloga y dictamina cuál es el patrimonio urbano de esta ciudad.
\end{abstract}

Palabras clave: espacio, configuraciones espaciales, patrimonio, Quibdó, Pacífico colombiano, trazado urbano, territorio.

Para citar: Rodríguez Echeverry, N. (2021). Trazados y configuraciones espaciales: tras la huella del patrimonio urbano en Quibdó, Colombia. Perspectiva Geográfica, 26(2), 93-111. https://doi.org/10.19053/01233769.12684

Doctora en Ciencias Sociales y Humanas de la Pontificia Universidad Javeriana. Profesora e investigadora del Departamento de Arquitectura de la Facultad de Arquitectura y Diseño de la Pontificia Universidad Javeriana de Bogotá, Colombia. Grupo de Investigación Transiciones Territoriales. Correo: rodriguezn@javeriana.edu.co. Orcid: https://orcid.org/0000-00018869-0947 


\title{
Layouts and spatial configurations: on the trail of urban heritage in Quibdó, Colombia
}

\begin{abstract}
The article makes a reflection on the conformation of the urban layout of the city of Quibdó, in the Colombian Pacific, in relation to the spatial configurations that constitute it and that this constitutes. This proposal understands the conformation of the layout and the spaces in correlation with diverse social relations, in the knowledges, understandings, appropriations and experiences of the local groups, as well as in the relations of the settlers with the physical and natural environment, as weavings of relations and dynamics that build space and territory. From the research carried out in the urban structure of Quibdó, spatial configurations and characteristic layouts of the city are identified, through which are traced understandings, identities and forms of thought and organization associated with space. The inquiries lead to the detection of elements of value associated both with spatialities and layouts that allow glimpses of heritage elements linked to the urbanscape. It is a bet to understand other forms of approach that put in tension the hegemonic look that catalogs and dictates what is the urban heritage of this city.
\end{abstract}

Keywords: space, spatial configurations, heritage, Quibdó, Colombian Pacific, urban layout, territory.

\section{Traçados e configurações espaciais: após a pegada do patrimônio urbano em Quibdó, Colômbia}

\begin{abstract}
Resumo: No artigo faz-se uma reflexão sobre a conformação do traçado urbano da cidade de Quibdó, no Pacifico colombiano, em relação às configurações especiais que o constituem e que este constitui. Esta aposta compreende a conformação do traçado e os espaços em correlação com diversas relações sociais, nos conhecimentos, nos entendimentos, as apropriações e as vivências dos grupos locais, bem como nas relações dos habitantes com o ambiente físico e natural, como tecidos de relações e dinâmicas construtoras de espaço e território. A partir das pesquisas realizadas na estrutura urbana de Quibdó identificam-se configurações espaciais e traçados característicos da cidade, através dos quais se rastreiam compreensões, identidades e formas de pensamento e de organização associadas ao espaço. As indagações suscitam a detecção de elementos de valor associados às espacialidades e traçados que permitem vislumbrar elementos patrimoniais vinculados ao urbano. Trata-se de uma aposta em entender outras formas de aproximação que ponham em tensão o olhar hegemônico que cataloga e dita qual é o patrimônio urbano desta cidade.
\end{abstract}

Palavras-chave: espaço, configurações espaciais, patrimônio, Quibdó, Pacífico colombiano, traçado urbano, território. 


\section{Introducción}

El Pacífico colombiano, en la región occidental del territorio nacional ${ }^{3}$, es una de las zonas de mayor biodiversidad en el mundo. Comprendida entre la frontera con Panamá - zona del Darién- y la frontera con Ecuador — zona del río Mira-, la región del Pacífico se constituye en área natural de riqueza ecosistémica, de variedad ecológica, hídrica y forestal; adicionalmente, por estar ubicada en una zona de convergencia intertropical (ZCIT), presenta alta humedad y precipitaciones ${ }^{4}$. Así mismo, ostenta condiciones selváticas y vegetación agreste: selva, bosques, montes, valles y cerros, entre otras formaciones naturales enmarcadas en relieves variados, montañosos y accidentados de la cordillera Occidental que, para Romero (2009), “es más que un referente geográfico" en tanto incide en otros aspectos, como "en lo económico", las vías de comunicación y el transporte (p. 9), pero también en lo social y lo cultural, ya que condiciona los modos de vida generando relaciones y respuestas espaciales y funcionales por parte de los grupos humanos.

En relación con lo anotado, es también el Pacífico colombiano un territorio hídrico, donde el mar, los ríos, los afluentes y las quebradas - entre otras formaciones - lo riegan, surten y bañan, entrelazando los cuerpos de agua y trenzando los espacios y los territorios; allí se destacan ríos como el Atrato, el Baudó, el San Juan, el Calima, el Micay, el Patía y el

3 Romero (2009) explicita que "La región está localizada al occidente de Colombia sobre una superficie superior a los 116 mil $\mathrm{km}^{2}$. De oriente a occidente, está enmarcada por la Cordillera Occidental y el litoral del Océano Pacífico extendiéndose, de norte a sur, entre el Golfo de Urabá, sobre el mar Caribe, y la frontera con Panamá, hasta la frontera con Ecuador" y que es "una unidad geográfica y una región natural que abarca los territorios de cuatro departamentos: Chocó, Valle del Cauca (Buenaventura), Cauca y Nariño" (p. 7)

4 Según Guzmán et al. (2014), "Los procesos de lluvias están condicionados por el movimiento de la ZCIT - rama Pacífica de sur a Norte y de Norte a Sur durante el año, los cuales se combinan con efectos orográficos por la presencia de varios accidentes geográficos y de la Cordillera Occidental. La orientación de las cadenas montañosas (Serranía del Baudó y las estribaciones de la cordillera Occidental), actúa como una barrera para las masas de aire tropical provenientes del Océano Pacífico que descargan su humedad en las laderas occidentales de las cadenas montañosas a modo de precipitaciones orográficas" (p. 30).
Mira, entre otros. Un escenario de conformación de ensenadas, bahías, playas, playones, morros, esteros, manglares, acantilados, humedales y páramos, entre otras formaciones naturales que evidencian riqueza y diversidad geográfica. En este orden de ideas, se trata de un entorno hídrico en el cual la geografía contribuye a resolver la comunicación a través de rutas fluviales (Romero, 2009, p. 11), ya que la región Pacífica y la cuenca del Atrato son parte de la red fluvial navegable de Colombia (Quintero et al., 2020, p. 55). Sin embargo, la relación con el agua va más allá, es lugar y medio de vínculos y relaciones, donde interacciones, entendimientos y dinámicas entre el medio natural y el hombre dan vida a distintas representaciones y prácticas ambientales, económicas, sociales y culturales.

El territorio del Pacífico es entonces entorno acuático fluvial y marítimo, generador de lugares productivos asociados a la pesca y la captura, pero también entorno de tierras fértiles y suelos de riqueza mineral. Así mismo, es un escenario de diversidad enmarcado en un clima tropical de altas temperaturas que alberga variedades de flora y fauna; así, presenta mangles rojos, blancos, negros, palmeras y bromelias, entre tantas especies vegetales, pero también peces, reptiles, cangrejos, mamíferos y aves, entre otros especímenes animales que conforman y dan cuentan de la biodiversidad y la riqueza del Pacífico colombiano. Todo un acontecimiento de condiciones geográficas que hace posible la conformación de ecosistemas y espacios vitales, esto es, la interacción de distintas formas de vida que se construyen y entrelazan.

Es así como las diversas interacciones se construyen y cohabitan con los pobladores de la región, dando cuenta de modos productivos y económicos y de prácticas sociales, políticas y culturales. Como indica Restrepo (2016), "entre el 92\% y 96\% de la población de esta región es afrodescendiente" (p. 190); se trata de grupos humanos que históricamente han habitado y construido espacios y territorios, evidenciando de este modo entendimientos y comprensiones del 
medio físico, natural y del entorno, así como construcción de tejidos de relaciones del saber y del hacer.

En este sentido, y siguiendo a Restrepo (2016), "con base en disímiles amalgamas de legados africanos, aborígenes y europeos, estas poblaciones no sólo han aprovechado tradicionalmente las selvas, ríos y esteros, sino que además han creado nuevas modalidades de organización social y sistemas de pensamiento" (p. 190). Formas de entender, habitar y construir el territorio solventadas en el tiempo y materializadas en el espacio; selvas, costas, ríos, montes que se viven, habitan y apropian dejando improntas en tanto configuraciones espaciales rurales y urbanas.

De esta manera, en el entendimiento de las constituciones espaciales en el Pacífico colombiano, se considera relevante reflexionar sobre la conformación que deja como impronta el trazado urbano en la ciudad de Quibdó, en el departamento del Chocó, una de las principales ciudades del Pacífico que tiene la particularidad de no ser un lugar costero, sino de estar asociada al río. Quibdó se encuentra en la zona del Medio Atrato, cerca al Carmen del Atrato, al Alto Baudó, a los ríos Quito y Lloró y al departamento de Antioquia; una zona que comparte características biodiversas del Pacífico colombiano y que se destaca por ser parte del Chocó Biogeográfico (Figura 1). Es así como, surcado por cuerpos de agua como el Atrato, el Quito y el Cabí, y quebradas como la Yesca y la Aurora, en condiciones topográficas de pendientes, colinas, montes, llanuras y laderas, rodeado deexuberante vegetación y con población mayoritariamente afrodescendiente, se alza Quibdó: un escenario de diálogo y encuentros con los entendimientos de sus grupos humanos.

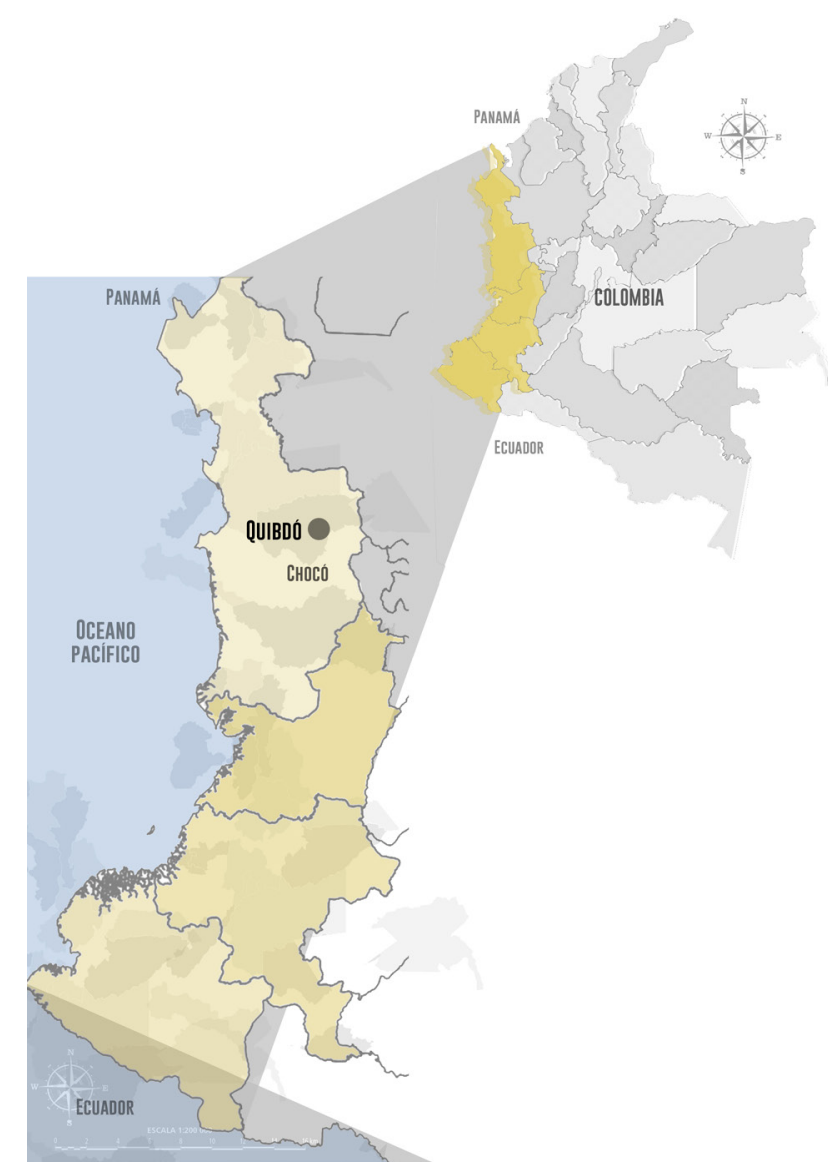

FIGURA 1. Localización de Quibdó, Pacífico colombiano

FUENTE: representación gráfica de María Paula Malaver. 


\subsection{Tejiendo trazados y entrelazando espacialidades}

Entender el hecho físico en el entramado de diversas relaciones sociales y de poder supone hacerlo en vínculo con los saberes y formas del hacer locales en (y desde) el lugar de ordenación. En esta perspectiva, para Crespo y Vila (2014), "Históricamente los saberes y conocimientos ancestrales, tradicionales y populares han sido víctimas de lógicas de colonialidad de poder y de saber" (s. p.). Miradas hegemónicas que, en el caso de Quibdó, desestiman la construcción social, no evidencian las aprehensiones locales e igualmente invisibilizan interconexiones y constituciones del espacio con el entorno.

Ante lo expuesto, desde la presente meditación, se entiende el espacio como "construcción social", más allá de asumirlo como escenario, telón de fondo o ámbito donde se posan elementos físicos y naturales, sino que se genera a partir de relaciones y, a su vez, también es generador de relaciones (cfr. Rodríguez, 2019). Por tanto, el espacio se entiende como "producto social" de "responsabilidad política" (Maseey, 2012, p. 9) y donde, siguiendo a Ramírez y López (2015), "se dan los vínculos, las relaciones e interacciones, que llevan a la construcción, transformación, percepción y representación de la realidad" (p. 18).

Ahora, se medita el espacio como construido en el marco de las relaciones sociales (Maseey, 2012; Rodríguez, 2019), pero también en las relaciones entre el hombre, la naturaleza y el medio (Santos, 2000), y en donde "las técnicas constituyen un conjunto de medios instrumentales y sociales, con los cuales el hombre realiza su vida, produce y, al mismo tiempo, crea espacio" (Santos, 2000, p. 27). En este orden de ideas, se apuesta por comprender las espacialidades en tanto construcciones, elementos y hechos físicos

5 Siguiendo a Harvey (2018), "Las construcciones sociales del espacio y del tiempo no salen de la nada, sino que son modeladas a partir de las diversas formas de espacio y tiempo que los seres humanos encuentran en su lucha por la supervivencia material" (p. 274). proyectados y materializados en el trazado urbano de Quibdó, en interacción e interrelación con el entorno ${ }^{6}$ y las lógicas de sus pobladores.

En esta perspectiva, interesa indagar sobre los teji$\operatorname{dos}^{7}$, las imbricaciones y las urdimbres que solventan las comunidades, que evidencian las relaciones que subyacen y emergen de estas y que derivan en la emergencia de configuraciones espaciales. $\mathrm{Al}$ respecto, se entiende el espacio geográfico como realidad natural, material y social (Claval, 2002, p. 29) y, además, en interrelación con las apuestas de grupos humanos que edifican territorio. Y es que el territorio, más allá de asumirse como una porción de tierra, se entiende en el marco de la construcción de relaciones e imbricaciones: para Restrepo (2016), una "forma de reflexividad política y de apropiación espacial"(p. 190); para Hadad y Gómez (2007), como representación de una "configuración social no exentade conflictos que involucran a una diversidad de actores que comparten el espacio" (p. 8); para Silva (2016), como "construcción sociocultural de largo aliento, dinámica y conflictiva, donde las comunidades e instituciones son los actores centrales de esa construcción" (p. 633), pero también, como destaca Haesbaert (2011), con carácter dinámico, multiescalar y multidimensional.

Frente a lo expuesto, interesa reflexionar sobre el trazado urbano en Quibdó en el marco de las apropiaciones, las vivencias, las experiencias, las interrelaciones, los tejidos y las redes, en las dinámicas y movimientos generadores, a su vez, de otros territorios, pero también en la materialización de los conocimientos y saberes; unos y otros se establecen y emergen de sus pobladores locales en tanto constructores de espacialidades. En este orden de ideas, se

6 Hacemos énfasis en la reflexión de Sorre (1943) respecto a estudiar desde la geografía las formas en que los hombres organizan el espacio en relación con el hábitat. Siguiendo a Vargas (2012), "El hábitat en Sorre es el área habitada por una comunidad, la cual la ha organizado, por lo tanto, se trata de una forma humanizada del espacio que expresa sus múltiples relaciones entre el ser humano y el ambiente que lo envuelve" (p. 315).

7 Para profundizar y ampliar lo referente a la organización del espacio en relación con las redes y las relaciones sociales, véase a Paul Claval (2002). 
trata del trazado como generado y generador, creado y creador, como conformado y conformador, entre múltiples interrelaciones leídas en las huellas, los elementos y las espacialidades erigidas; un trazado que, siguiendo a Capel (2002), puede relacionarse con las etapas de la evolución histórica (p. 439), con la forma espacial en relación con las "pruebas tangibles" para "definir una sociedad" (Harvey, 1977, p. 215), con la observación de la forma vinculada al crecimiento, a la manera de implantación, a la expansión que permite concebir las disposiciones de las tramas, las particularidades y los significados de las espacialidades, entre otros posibles análisis.

Ahora, la apuesta por tejer trazados y espacios en Quibdó se emprende desde la perspectiva que los vislumbra como patrimonio. Sin embargo, es esta una aproximación del patrimonio que lo entiende como "construcción social” que, siguiendo a Prats (1997), "no existe en la naturaleza, no es algo dado, ni siquiera un fenómeno social universal", pero que "es un artificio, ideado por alguien (o en el curso de algún proceso colectivo), en algún lugar y momento, para unos determinados fines, e implica finalmente que es o puede ser históricamente cambiante, de acuerdocon nuevos criterios o intereses que determinen nuevos fines en nuevas circunstancias" (p. 20).

Patrimonio que se construye en el tiempo, y que en lo urbano entiende el hecho físico y su historiaen interacción con las condiciones geográficas y naturales, así como las conformaciones que emergen como producto de apropiaciones, significaciones e identidades que tramitan sus pobladores. Siguiendo a Lee Alardín (2016), se trata de un patrimonio urbano desde un "concepto ampliado" que apunta "hacia una visión incluyente e integradora del patrimonio, la historia, el paisaje y la identidad colectiva" (p. 117). En este sentido, un patrimonio urbano en el Pacífico que, siguiendo a Mosquera (2010), "se refiere a hábitats humanos que expresan tanto valores culturales como unos ideales y aspiraciones de sus moradores con respecto a la vivienda", pero también "los modelos urbanos y los componentes del ordenamiento territorial" (p. 15).

En directa correlación con las construcciones espaciales en el Pacífico colombiano, la presente indagación plantea que el trazado urbano y las conformaciones espaciales en Quibdó responden a las condiciones geográficas y naturales del lugar y se solventan en entendimientos, saberes y apropiaciones que se hallan atravesadas por diversas relaciones sociales, del saber y del hacer. Del mismo modo, propone que dichas formas y constituciones espaciales, en tanto huellas e improntas del tiempo en el espacio, se constituyen en vestigios del patrimonio urbano de la ciudad, edificadas, identificadas y apropiadas por los pobladores locales y no necesariamente legitimadas bajo las lógicas hegemónicas estatales o expertas.

En efecto, se persigue la identificación de configuraciones espaciales conformadoras del tejido urbano en Quibdó, que mediante la detección y la caracterización de conformadores urbanos, elementos constitutivos y valores patrimoniales de significación permitan aproximarse al entendimiento del patrimonio urbano. De igual manera, se busca subrayar los elementos geográficos y naturales como configuradores de espacialidades en relación con lo urbano patrimonial.

Por tanto, son trazados y constituciones espaciales en clave de patrimonio urbano, en la convicción de que hacen parte de la memoria colectiva y las identidades de una ciudad y sus pobladores, que son huellas de la forma de representación histórica materializada en las maneras de implantación sobre las que se alzan soluciones formales con estéticas particulares. Conformaciones espaciales que dan cuenta de la historia urbana, que se constituyen en repertorio de las formas y soluciones urbanas y arquitectónicas y que evidencian formas de pensamiento, entendimientos y apropiaciones con (y desde) el medio de implantación de las comunidades de Quibdó. 


\section{Entre trazados y espacios: configuraciones espaciales}

A mediados del siglo XIX, a orillas del río Atrato, se divisa Quibdó ${ }^{8}$, ubicación que la convierte en punto de conexión regional y nacional estratégico, de carácter económico y comercial, de interés para la erección de infraestructura, pero también de importancia dadas sus riquezas minerales de oro, plata y platino; unos y otros aspectos que traen consigo la llegada de población inmigrante que cohabita con los pobladores locales negros e indígenas. Si bien las dinámicas y tensiones entrelos grupos sociales que marcan la historia y la conformación de la ciudad no son tratadas en el presente texto por rebasar su alcance, lo que es pertinente anotar es que las tensiones entre los grupos tienen repercusiones en la formación urbana, esto es, en la generación de zonas, periferias,límites y referencias físicas sobre el espacio, que marcan la historia y las dinámicas de la urbe (cfr. Rodríguez, 2019). Para Zambrano (2010), prácticas segregacionistas hacia los pobladores negros que "va a tener expresiones urbanas que han sido definitivas en la historia de Quibdó" (p. 57).

Es así como la interrelación de hechos históricos, políticos y económicos y las dinámicas sociales y culturales, en conjunción con las condiciones naturales y físicas del lugar, permiten rastrear formas de ordenamiento y funcionamiento. En síntesis, entendimientos de las formas de disposición y organización de la trama urbana vinculadas con las espacialidades.

Para Gilma Mosquera (2010), el proceso histórico de poblamiento de las tierras del Pacífico distingue la configuración de hábitats humanos y Quibdó corresponde al hábitat minero de colonización española, y precisa que "el segundo ciclo comienza a fines del siglo XVII con la instalación de Reales de Minas durante la colonia española y perdura hasta principios del siglo XIX" (p. 29). Quibdó se identifica como uno de los mayores centros mineros.

\section{Entrelazando espacios: hacia la comprensión del trazado urbano en Quibdó}

En su morfología, Quibdó evidencia disposiciones, entendimientos y acontecimientos que la conforman y la edifican. Si bien el trazado de la ciudad - producto de la superposición de diversos eventos en el tiempo y en el espacio - constituye un resultado dinámico en constante cambio, también es un hecho físico que permite indagar conformaciones y dinámicas a través de sus formas, elementos y espacios. Calles, carreras, edificaciones, infraestructuras, alamedas y barrios, pero también puertos, embarcaderos, patios traseros, huertos, pasarelas y palafitos, entre otros, evidencian las conformaciones espaciales que constituyen la urbe.

$\mathrm{Al}$ respecto, el trazado urbano se entiende desde lo heterogéneo, lo plural, lo diverso y lo dinámico. Así mismo, se subraya que, al referirse al trazado, se hace referencia a las tramas, redes e imbricaciones, a los movimientos y desplazamientos, en un intento por tejer formas de organización espacial en el Pacífico colombiano, con lo cual no se quiere forzar ni generar modelos rígidos de análisis.

Ahora bien, en el entendimiento de la unidad urbana-territorial, el entramado de diversos elementos - como los constitutivos asociados a lo urbano, los elementos conformadores, los valores y significados, las relaciones y las dinámicas en Quibdó - permite identificar unidades de análisis en tanto configuraciones espaciales. Así, se referencian las configuraciones de río y puerto, la central, la de río y quebrada, la de camino y centro y las de puntos tensores, que posibilitan acercarse a la conformación de las tramas urbanas y con esto vislumbrar representaciones del patrimonio urbano de Quibdó (Figuras 2 у 3$)$. 


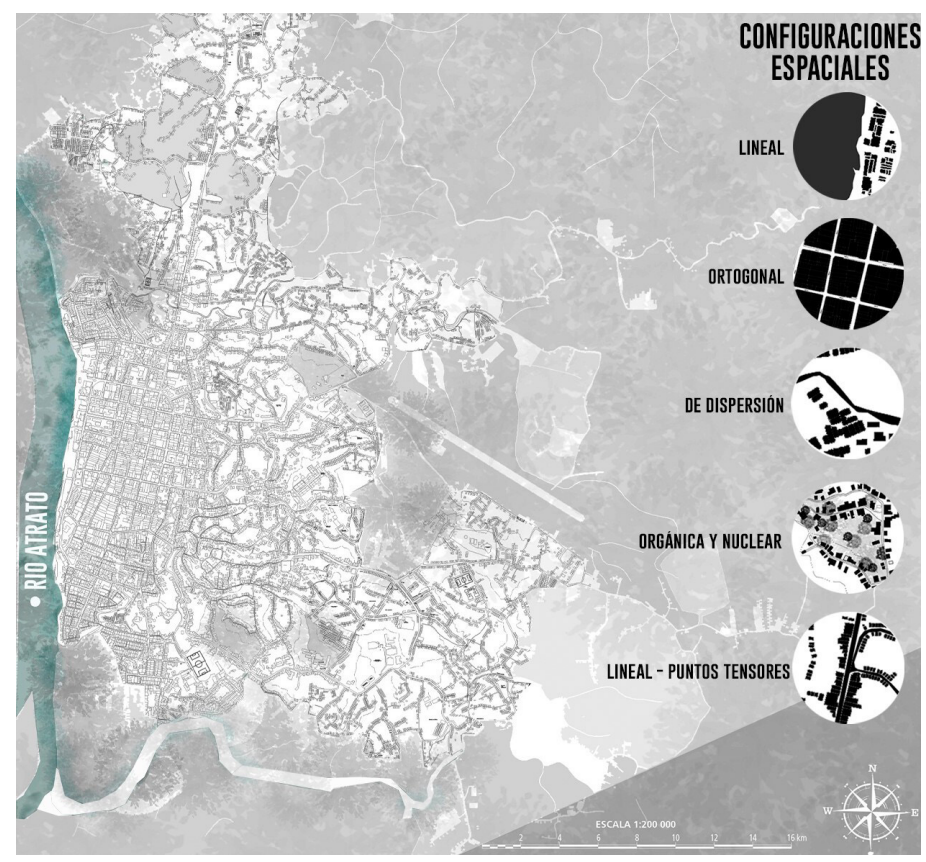

FIGURA 2. Configuraciones espaciales

FUENTE: análisis propio; representación gráfica de María Paula Malaver.

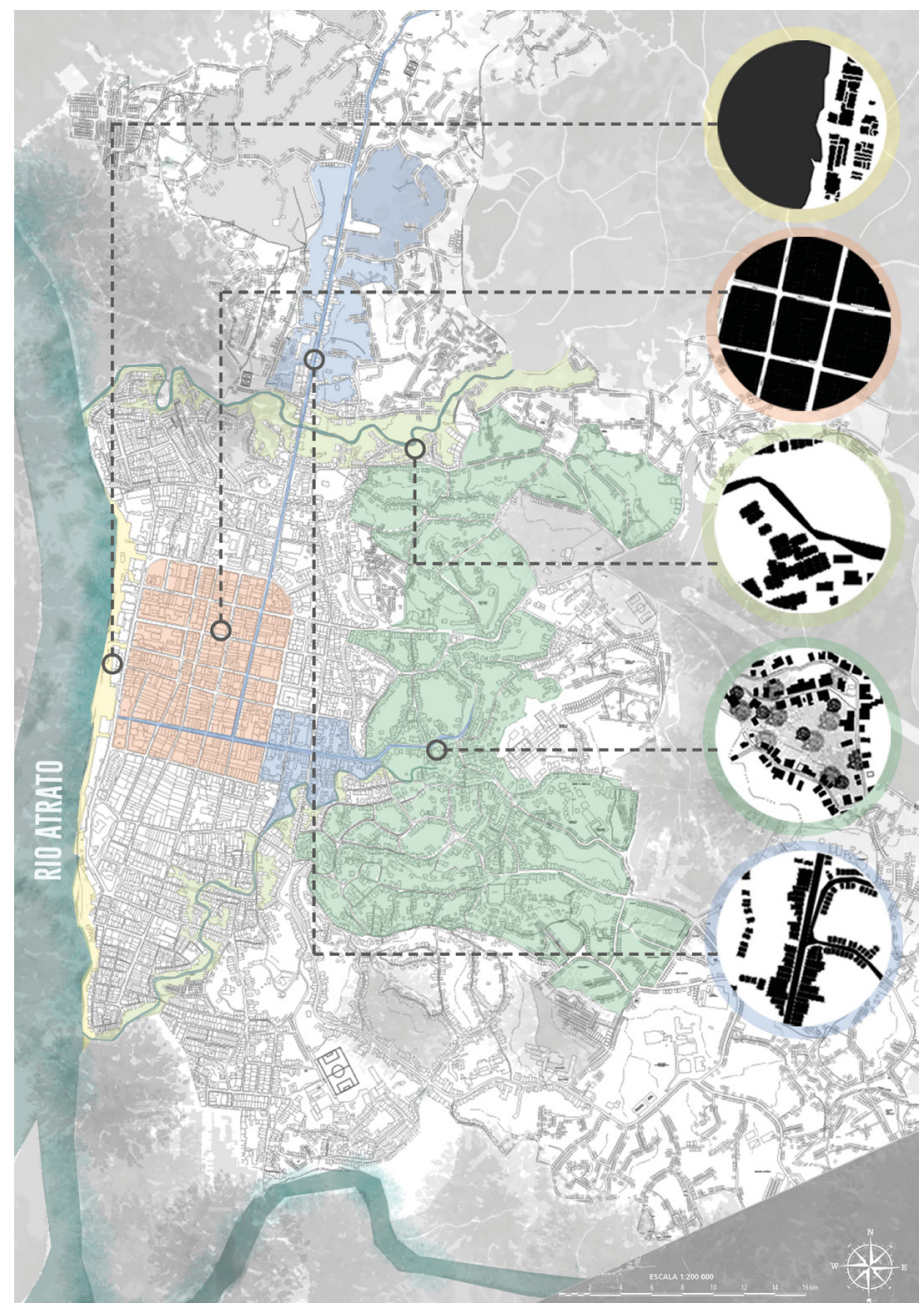

FIGURA 3. Localización de las configuraciones espaciales

FUENTE: análisis propio; representación gráfica: María Paula Malaver. 


\subsection{Configuración lineal: río y puerto}

Quibdó y sus relaciones con el río se solventan en dinámicas ambientales, económicas, comerciales, sociales y culturales establecidas en el tiempo. Es así como en el margen del río Atrato se conforma un eje comprendido entre las quebradas el Caraño (al norte), la Yesca (al sur) y el eje de la carrera Primera. La detección de elementos constitutivos asociados a lo urbano y lo territorial permite entender este eje como unidad que responde a una forma de implantación irregular; espacialidad que sigue la sinuosidad del río, soportada en condiciones geográficas sobre las que se posan y distinguen edificaciones (algunas palafíticas), espacios públicos y edificios representativos y simbólicos que generan un perfil urbano hacia la carrera Primera y conforman un continuo de paisaje hacia el costado del río (Figura 4).

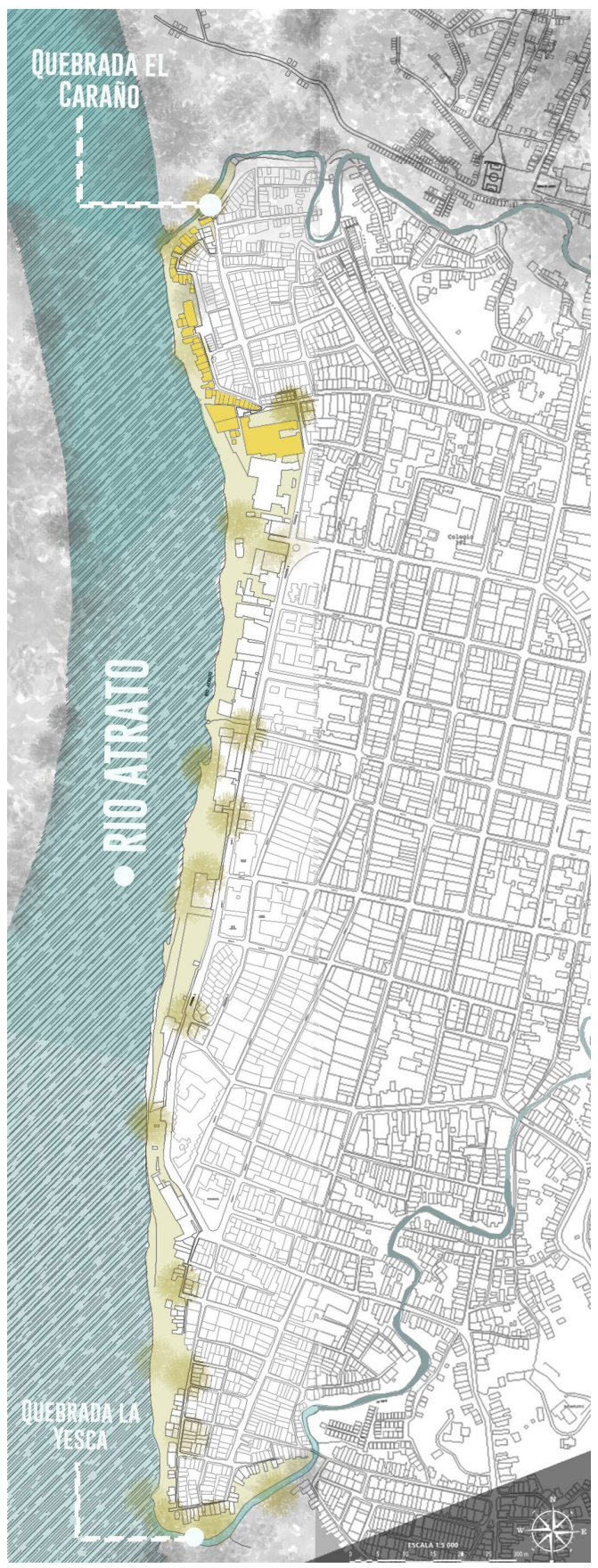

FIGURA 4. Configuración lineal: río y puerto

FUENTE: análisis propio; representación gráfica: María Paula Malaver. 
Se trata de elementos conformadores de orden territorial que evidencian que en la ordenación de la pieza entre el río y las quebradas se tejen los elementos naturales y geográficos con los arquitectónicos y urbanos, donde se destaca lo natural como determinante en la generación de los espacios, más allá de entenderse como límite o telón. Ahora, se enfatiza que la unidad urbana es punto de intercambio y enlace comercial de productos con la región y, por tanto, articuladora y propulsora de sitios de contacto, dinamizadora de actividades y nodo de infraestructura de la red fluvial de transporte.

En cuanto a los elementos conformadores de carácter histórico, se distingue como lugar de memoria. Hacia la ribera del río, conserva los vestigios de los antiguos puertos, como el Puerto Pequeño, el Platanero, La Imprenta, el de La Confianza, el Arrimadero y el Baulero, entre otros que dan cuenta del otrora atracadero de embarcaciones y canoas y del espacio de aterrizaje de hidroaviones. En síntesis, se trata de conformaciones espaciales sobre la ribera del Atrato que son parte de la historia de la ciudad y del territorio y de los valores intrínsecos, en tanto huellas y lugares de la memoria individual y colectiva.

Así mismo, asociado a lo histórico, lo arquitectónico y lo urbano se distinguen espacios distintivos que se posan en el margen del río y se relacionan también con la emblemática carrera Primera. Inmuebles como el Antiguo Convento, hoy Palacio Episcopal - Bien de Interés Cultural del carácter nacional (BICN)- , destacan por su espacialidad y materialidad; también sobresalen la plaza de mercado, por sus significados, apropiaciones e identidades, y el malecón, como espacio público emblemático y de significación en tanto lugar de encuentro, memoria y simbologías. Se trata de patrimonios de la urbe que confieren a la unidad valores sustentados en la representatividad, lo estético, lo histórico y lo simbólico.

Es de anotar que la unidad espacial evoca también hechos históricos de la ciudad referidos a su fundación y a las etapas sucesivas de conformación. Es este un punto que reseña la ubicación de los pobladores negros e indígenas ${ }^{9} \mathrm{y}$ su posterior desplazamiento a otras áreas, hechos históricos materializados en el espacio que dan cuenta de procesos de segregación y resistencia. Así, es un espacioque revela las significaciones sociales que son parte de las representaciones de la memoria colectiva y que denotan, a su vez, valores simbólicos que se tejen en - y desde - el lugar.

Del mismo modo, la conformación espacial se consolida como punto social y cultural. Es escenario de dinámicas colectivas y de encuentro de las comunidades en espacios como el malecón y la plaza de mercado, lugar de congregación de los pobladores donde lo sagrado tiene cabida en las celebraciones y balsadas en honor a San Pacho - patrono de Quibdó - y donde lo colectivo se vive en todo el entorno del majestuoso río Atrato. Unidad espacial conformada y conformadora de patrimonio material e inmaterial encarnados en los diversos puntos y espacios señalados.

En síntesis, la unidad urbana condensa valores patrimoniales de conjunto y de paisaje representativos de la ciudad y del Chocó que permiten leerla como conformación lineal asociada al río y a los puertos. Una conformación espacial donde los valores ambientales distinguen los recursos naturales y las condiciones geográficas como parte constitutiva y transversal a los diversos atributos que soportan las valoraciones, y donde se destacan los valores paisajísticos que tejen los atributos naturales con la arquitectura y lo urbano, conformando un entorno de paisaje de interés urbano, cultural y ambiental.

En cuanto a lo urbano y lo territorial, la valoración destaca el ser lugar de relaciones con la ciudad y el territorio asociadas a lo fluvial. Esta conformación lineal destaca puntos de contacto, como los vestigios de los antiguos puertos, hoy resignificados en las áreas de arribo y desembarcadero, y los espacios

9 Para ampliar la referencia a la ubicación de los pobladores negros e indígenas en las barrancas lineales, véase González (2003). 
como el mercado y el malecón, pero también en las intersecciones con la trama urbana. Generación de calles de relevancia histórica que se prolongan en sentido oriente (hacia la zona centro) y generación de flujos hacia el río y la ciudad (antiguos caminos) que muestran formas de disposición urbana en conexión con el río.

Cabe distinguir también que la configuración lineal río y puerto se soporta en valores históricos que permiten leerla como documento, en el entendido de que da cuenta de la historia urbana, que faculta vislumbrar diversos momentos, eventos y dinámicas históricas, así como distinguir bienes patrimoniales. Finalmente, cabe anotar que esta configuración está atravesada y soportada en valores simbólicos y significaciones, en tanto lugar de vínculos, de prácticas sociales y culturales, de representaciones y expresiones, donde prima el reconocimiento y la apropiación por parte de las comunidades. En suma, se trata de una configuración espacial como manifestación de lo cultural.

\subsection{Configuración ortogonal: central}

En inmediaciones a la unidad de configuración lineal río y puerto, y como parte de la prolongaciónde los puntos conectores, se registra la unidad centro. Dicha configuración distingue elementos estructurantes históricos que destacan hechos y eventos en la ordenación de la ciudad. Es así como, para el siglo XVIII, esta área se relaciona con la conformación asociada al origen, y para comienzos del siglo xx, como lugar que aglutina actividades y poderes representativos de la urbe. Un espacio que, a su vez, simboliza el escenario de luchas y disputas sociales y los esfuerzos hacia a laconformación de un medio (cfr. Rodríguez, 2019), esto es, la materialización de lo urbano. En síntesis, la disposición ortogonal da cuenta de valores históricos y simbólicos que manifiestan en lo urbano las lógicas de pensamiento y las dinámicas imperantes para principios del siglo $\mathrm{xx}$.

Ahora, la unidad central aglutina diversos elementos conformadores y destaca el entrelazamiento de las condicionantes naturales y ambientales con los elementos urbanos y las dinámicas sociales, económicas, comerciales y políticas. Y es que las condicionantes geográficas de esta área determinan e influyen en su conformación; así, el suelo inundable al margen del río y la existencia de áreas pantanosas, en la parte oriental, generan la realización de diques aluviales, drenajes de aguas y relleno de suelos que permiten la edificación y la disposición del trazado. Se trata de condicionantes de un medio natural que se intervienen para erigir suelo sobre el cual urbanizar y levantar ciudad y, por ende, disponer de una traza ortogonal de calles y carreras que testifica la forma de implantación en un contexto de selva (cfr. Rodríguez, 2019); en suma, se trata de atributos ambientales y documentales asociados con el proceso histórico de conformación urbana (Figura 5).

En este contexto, y en concordancia con la ordenación y la delimitación de la unidad urbana, una serie de carreras - entre las que se distinguen la Primera, la Segunda y la Tercera-, en sentido norte-sur, se disponen entrelazadas con las calles - como el camino a Antioquia, la calle Pan de Yuca y la Yesca Grande - y conforman un damero contenido entre las carreras Primera y Séptima y las calles 20 y 31. Una traza que diferencia la disposición de manzanas regulares generadoras de perfiles urbanos sobre calles y carreras que albergan usos residenciales, comerciales, institucionales y administrativos, así como una arquitectura de valor contextual de conjunto (Figura 5). 


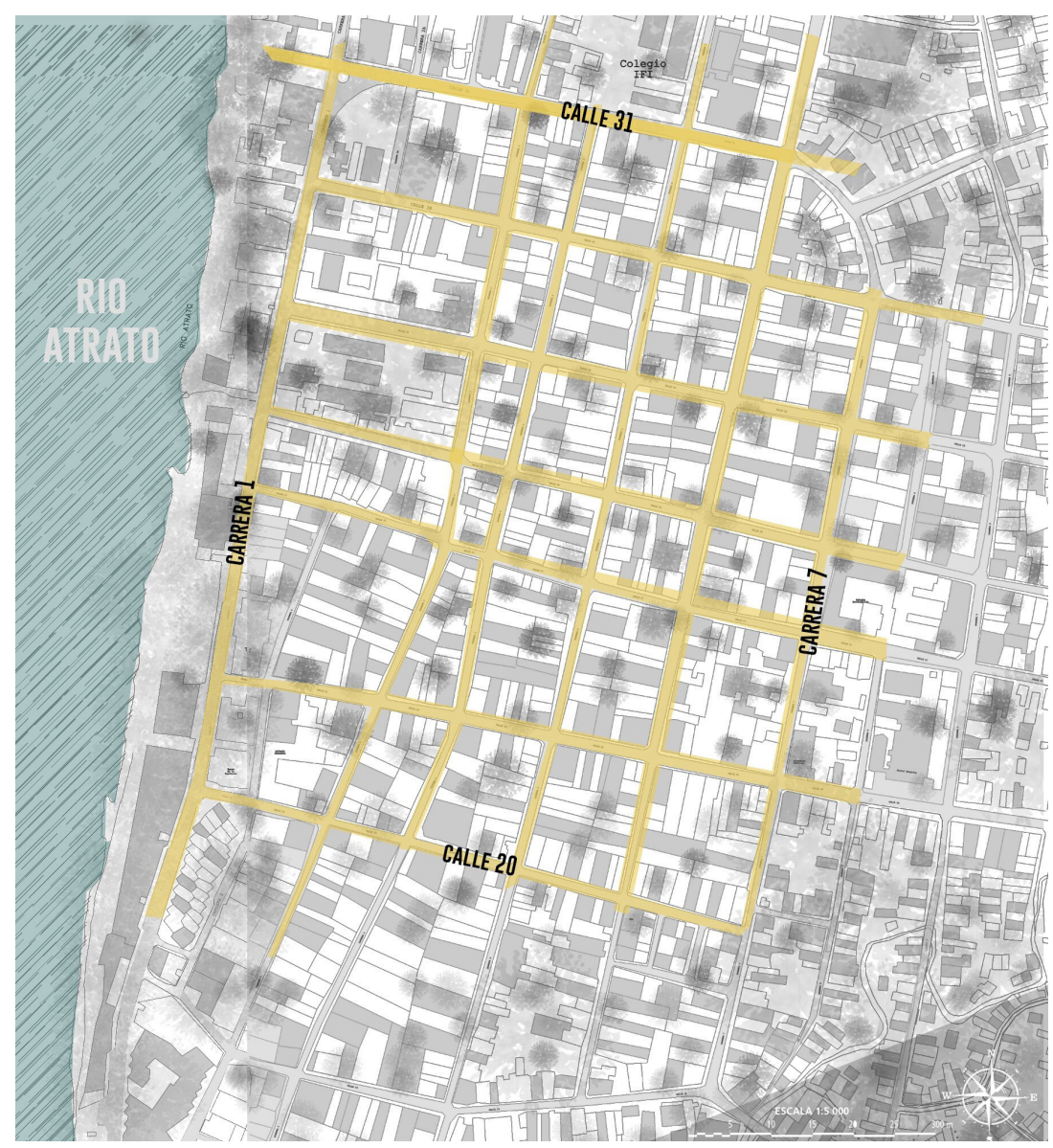

FIGURA 5. Configuración ortogonal central

FUENTE: análisis propio; representación gráfica: María Paula Malaver.

Ahora, en cuanto a los elementos conformadores paisajísticos, los continuos urbanos sobre las tres principales carreras destacan la representatividad del perfil urbano en tanto aglutina valores históricos, escénicos y de significación. Y es que en la configuración central se disponen inmuebles con atributos patrimoniales como la antigua Escuela Modelo (BICN), la Catedral y el Banco de la República, que ejemplifican valores asociados a la arquitectura republicana y moderna.

Además, los perfiles se constituyen en escenarios de representación arquitectónica y de significación en tanto conciertan atributos vinculados a bienes de índole religiosa, institucional, residencial y comercial, así como antiguas edificaciones referenciadas en la historia oral urbana de la ciudad ${ }^{10}$. Asimismo, se des-

10 Para ampliar la referencia específica a estos bienes, inmuebles y espacios, véase González (2003) y Rodríguez (2019). taca la relación de la zona de influencia de la unidad central con bienes patrimoniales declarados, como el Colegio Carrasquilla y la Cárcel de Anayanci, y con inmuebles representativos de la arquitectura residencial de la primera mitad del siglo xx, como las Cinco Quintas, la casa Díaz y la casa Cajales, entre otras. Perfiles urbanos y espacialidades que pese a las alteraciones y las desapariciones compendian valores escénicos y de significación urbana.

Ahora, la trama ortogonal resultante diferencia la generación de puntos y nodos de carácter social y simbólico que - además de congregar y reunir a la población - representan, localizan y simbolizan lo político, lo social y lo cultural. Así, se distingue el Parque Centenario, el Parque Manuel Mosquera Garcés, la Plaza Tomás Pérez y la Glorieta Benjamín Herrera, y bustos como el de Diego Luis Córdoba, el de César Conto y el Obelisco Simón Bolívar. Espacios públicos 
y elementos conmemorativos - como símbolos de memoria - que se posan en la escena urbana.

Finalmente, en la conformación central se destaca la potencia del elemento social y político manifestada en el espacio público, y con esto lo concerniente a lo simbólico y las significaciones. Generación de espacios de memoria reconocidos en lo público y en la escena urbana. Así, configuración como escenario de conmemoraciones y de expresiones, lugar de encuentro donde tiene cabida lo colectivo y lo cultural, representado en las procesiones y desfiles en el marco de las fiestas de San Pacho y en los recorridos para los difuntos camino al cementerio, entre otros. Espacio de valores simbólicos e intangibles como lugar de memorias que da cuenta de la dimensión física, social y política del espacio.

\subsection{Configuración de dispersión: río y quebrada}

La expansión de la configuración central hacia las zonas norte, sur y oriente encuentra como limitante física los cuerpos de agua que surcan el espacio, dando como respuesta adaptaciones arquitectónicas y urbanas, así como soluciones técnicas. Nuevamente las condicionantes geográficas son protagonistas en la conformación de la traza urbana y, con esta, de la arquitectura; formas del terreno e hidrografía que se hallan en relación con la implantación y las soluciones físicas de conjunto y, por tanto, atributos y valores asociados a lo ambiental y lo natural.

Retomando lo concerniente a la prolongación de la configuración central, las calles, carreras y agrupaciones espaciales se enfrentan a la presencia de quebradas como el Caraño, la Yesca y la Aurora, entre otros cursos de agua que contienen el crecimiento urbano, pero no lo frenan. Si bien la continuidad del trazado ortogonal se interrumpe, se registran soluciones urbanas y procedimientos técnicos como puentes y caminos que permiten sobrepasar los cuerpos hídricos y generar entrelazamientos. Estos diálogos entre lo natural y lo artificial resultan en formas adaptativas que destacan atributos asociados a la técnica local, pero también a la conformación de paisaje; unos y otros delatan valores técnicos, culturales y estéticos soportados en los elementos de conjunto y las cualidades de las unidades del paisaje.

Es importante señalar que los elementos conformadores naturales y ambientales están en conjunción con los entendimientos y los saberes de los pobladores locales - conformadores culturales - que materializan un tejido irregular de configuración dispersa que sigue los meandros y los cursos de las quebradas y sus afluentes, que no necesariamente están contenidas y delimitadas por eventos físicos. De esta forma se alzan soluciones palafíticas que enfrentan las altas precipitaciones e inundaciones y que permiten generar y ganar suelo edificable. Como explica Mosquera (2010), "la historia espacial de los poblados y Centros urbanos del Pacífico nos enseña que la implantación de las casas 'palafíticas' sobre el lecho del mar o el río no corresponde a la tradición” (p. 19), en el entendido de que las comunidades "se cuidaron siempre de edificar la vivienda en las zonas altas y protegidas de las crecientes del río" (p. 19).

Una situación análoga se registra en la configuración río y quebrada, donde se alzan soluciones palafíticas de viviendas en madera conectadas por medio de pasarelas, que hacen las veces de vías de comunicación que se prolongan, de manera lineal o discontinua, sin seguir parámetros, solo obedeciendo a las condiciones del lugar y a las comprensiones de los pobladores; generación de tramas irregulares que conectan y entrelazan las viviendas y agrupaciones. Siguiendo a Mosquera (2010), se trata de una "adaptación cultural a unas circunstancias espaciales y sociales", en donde se integran al "espacio urbano, conformando digitaciones y barrios anfibios" (p. 19).

Un sistema de relaciones de elementos conformadores culturales que evidencian las relaciones y las sinergias entre los sujetos y el contexto, entre los pobladores con el agua y el medio natural, pero también 
dinámicas sociales que dan cuenta de las prácticas de organización materializadas en asentamientos barriales, en la disposición de calles y puntos de reunión de carácter comunitario que se integran y conforman lo urbano (Figura 6). Atributos y valores asociados a las formas de hacer urbanismo y construir territorio leídas en las configuraciones dispersas en ríos y quebradas.

Tejiendo lo expuesto, se enfatiza que los elementos conformadores ambientales como los cuerpos de agua — más allá de barreras - se comprenden desde los entendimientos de los grupos afrodescendientes que habitan el Pacífico, así como en el marco de las construcciones sociales y culturales. En efecto, referencias a las relaciones parentales (Mosquera, 2010), a los asentamientos dispersos (Aprile-Gniset, 1993; Mosquera, 2010), a los grupos parentales (Aprile-Gniset, 1993; West, 2000), a los patrones de poblamiento a orillas de los ríos (West, 2000), al patrón de distribución espacial (Martínez, 2010) y a formas de asentamiento residencial disperso (Restrepo, 2016) permiten entender los posibles cruces e interrelaciones que acontecen en espacialidades como la de río y quebrada en Quibdó.

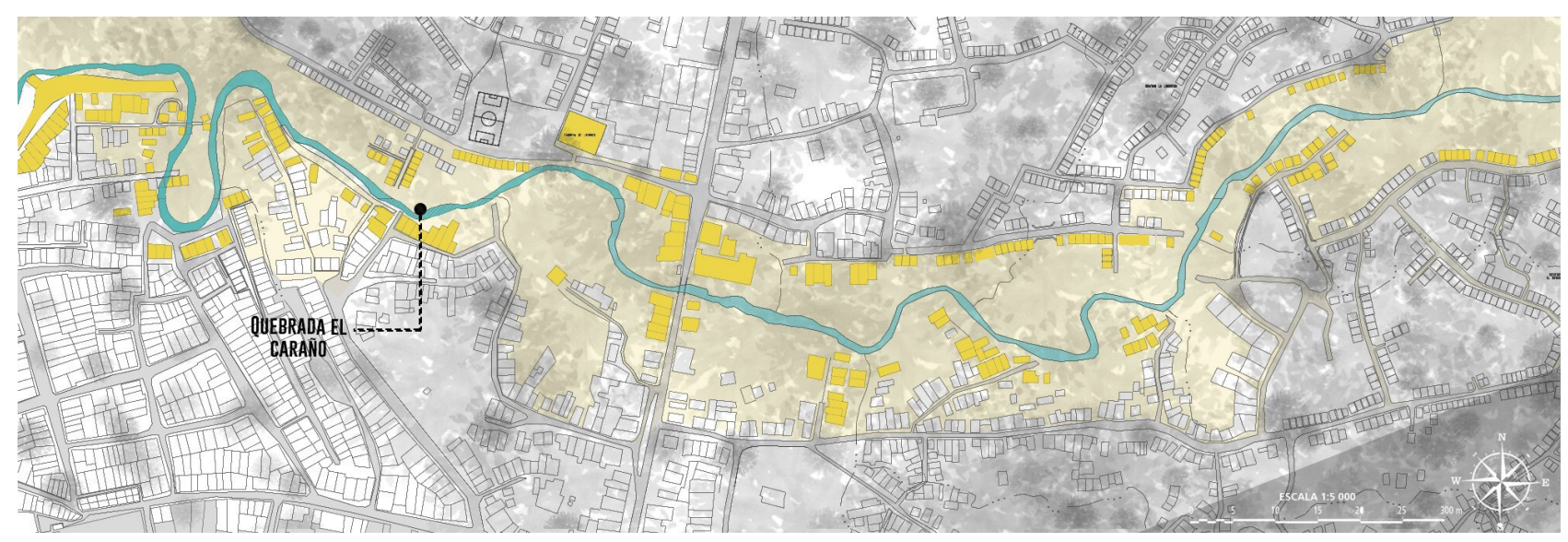

FIGURA 6. Configuración de dispersión: río y quebrada

FUENTE: análisis propio; representación gráfica: María Paula Malaver.

$Y$ es en este punto donde las territorializaciones ${ }^{11} \mathrm{y}$ movimientos se hacen potentes y se conciben los lazos y las conexiones con los territorios y los lugares de origen, procedencia y vivencia. Lógicas y prácticas de los pobladores del Pacífico materializadas en el espacio físico y urbano de Quibdó; tejidos de relaciones, saberes y tradiciones construidos con y desde el medio que dan cuenta de las formas de hacer urbanismo y territorio en relación con el agua, representados en la construcción de paisaje, en la escena urbana y

11 Para Silva (2016), la territorialización se entiende como un proceso de "apropiación y de construcción sociopolítica por parte de actores", pero también, siguiendo a Deleuze y Guattari (2000), en el sentido de la reterritorialización, la desterritorialización y las líneas de fuga. arquitectónica asociada a la técnica y la disposición de elementos, que también dan cuenta de las maneras de habitar y conformar un medio. En este sentido, es un lugar de transferencias de conocimientos que se entretejen con apropiaciones, vínculos e identidades y valores asociados a los patrimonios de las comunidades del Pacífico en Quibdó.

\subsection{Configuración orgánica y nuclear: camino y centro}

En Quibdó, la expansión urbana hacia la zona oriental se enfrenta a una topografía de laderas, colinas y montes, de vegetación agreste y con presencia de 
cuerpos de agua que brotan, se derivany se vierten en otros cuerpos y espacios. Si bien en las configuraciones central y río y quebrada se efectúan rellenos, en la configuración camino y centro la característica primordial es la adaptabilidad. En efecto, en esta configuración la topografía se constituye en la principal determinante formal, constructiva y urbana que origina soluciones orgánicas que se dispersan y multiplican de manera intermitente. De esta forma, se distinguen valores ambientales y urbanos, donde las formas del terreno vinculadas a la topografía y los cursos de agua se conjugan con las maneras de implantación, la trama y la configuración orgánica y nuclear.

Frente a esto, interesa mostrar que lo orgánico se enmarca en la apertura de caminos lineales que se abren espacio, adaptando y adaptándose a la topografía, y en la generación de trazados dinámicos y espacialidades dispersas. De esta forma, las viviendas se dispersan a medida que se abren los caminos, bordeando y acomodándose a su sinuosidad, lo que genera perfiles urbanos y agrupaciones espaciales promotoras de centros en tanto núcleos hacia el interior (Figura 7). Se trata de configuraciones orgánicas y nucleares representativas y distintivas del urbanismo de Quibdó que testifican los entendimientos y las soluciones técnicas locales, vinculan elementos constitutivos de conjunto en la urbe, dan cuenta del manejo de elementos propios de la cultura, vinculada al medio y al paisaje, y de la historia urbana y barrial; patrimonios del lugar que obedecen a las identidades y apropiaciones locales.

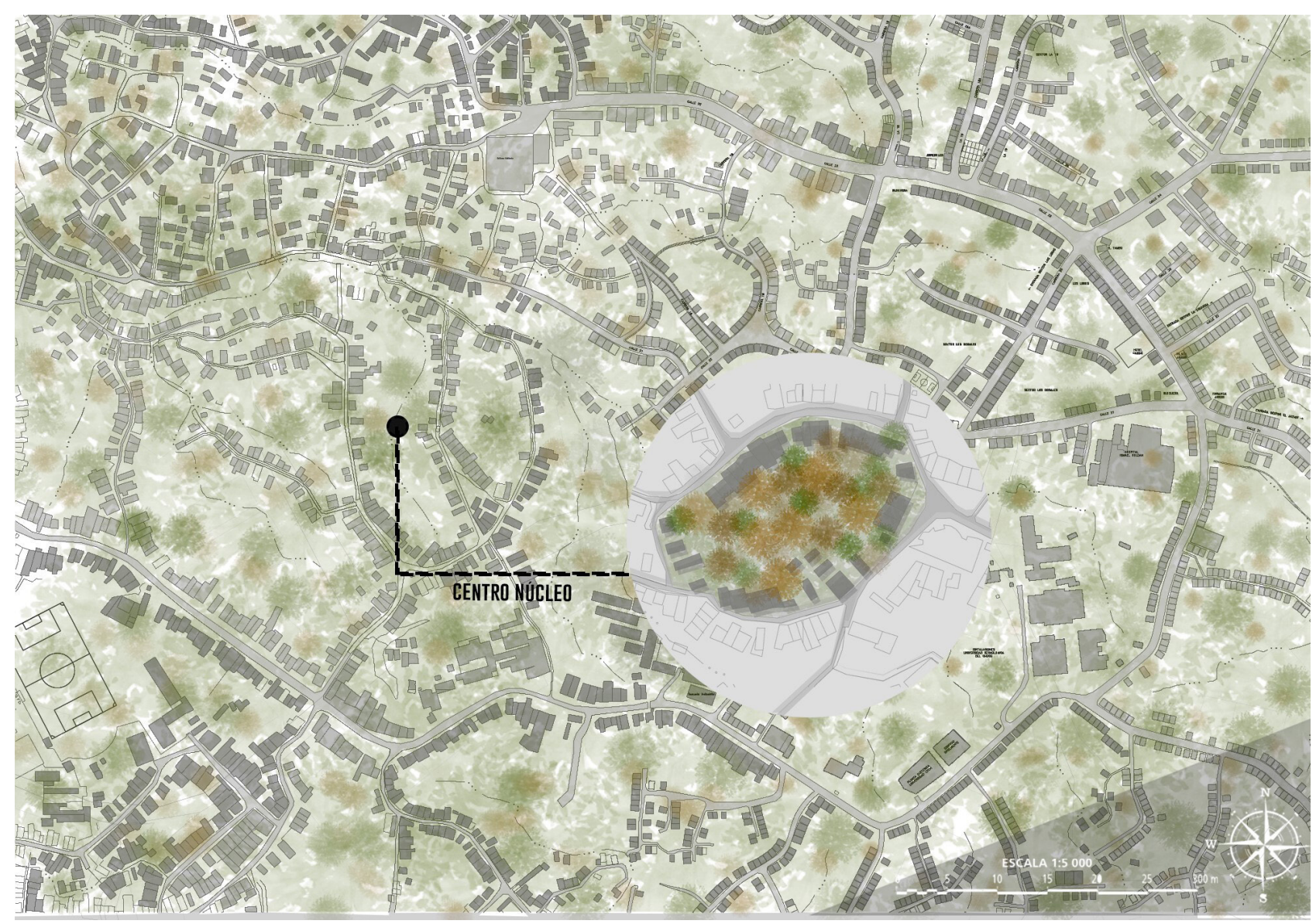

FIGURA 7. Configuración orgánica y nuclear: camino y centro

FUENTE: análisis propio; representación gráfica: María Paula Malaver. 
Ahora bien, asociado a lo urbano, se destaca la disposición del camino, así como el centro no edificado $^{12}$, que lo dotan de atributos de tipo ambiental y cultural; en relación con la vivienda, atributos asociados a la forma de hacer arquitectura - en relación con lo cultural - en la disposición de patios traseros y solares, así como zonas anexas posteriores como el baño, la cocina, la huerta y la azotea.

De este modo, al igual que en la conformación de dispersión, es posible reflexionar territorializaciones de prácticas, conocimientos y relaciones acontecidas en áreas rurales del Pacífico colombiano, como las de cercanía, amistad y familias ampliadas. Así, es un tejido de prácticas asociadas a los "núcleos veredales" en las tierras bajas del Pacífico referenciados por Mosquera (2010), lugares que distinguen "cultivos entre viviendas" transformados en "solares residenciales con 'patios' traseros cuyas dimensiones permiten ubicar el gallinero, sembrar algunas matas de plátano y árboles frutales y realizar actividades como el corte de leña y el secado de la ropa" (p. 44), entre otras transferencias asociadas al patrimonio cultural.

En suma, se trata de una espacialidad orgánica donde es posible entender la construcción social y cultural del espacio, las formas de apropiación, ordenamiento, representación y pensamiento de sus pobladores en relación con la construcción de hábitats y de un medio. Son valores que evidencian las transferencias y constituciones de los grupos en contexto urbano y que dan cuenta del proceso urbano en Quibdó, pero que también son de índole estética, en relación con la formación de paisaje, el manejo de la técnica y la conformación arquitectónica, y de significación, reflejada en las apropiaciones, las identidades, la generación de códigos y toponimias locales asociadas al lugar, y en valores comunitarios manifestados en el apoyo y la colaboración que se materializan en la agrupación y el barrio, en tanto representación urbana.

\subsection{Configuración lineal articular: puntos tensores}

Al transitar la trama urbana de Quibdó se identifican conformaciones lineales que conducen a puntos definidos que eventualmente se prolongan. Formaciones generalmente continuas que se abren paso con el fin de comunicar puntos y que, además de tejer espacialidades, las generan actuando como tensores y atractores de actividades y desarrollos. Ahora bien, el camino o vía que hace las veces de vector suele disponerse con el fin de conectar un último atractor, adquiriendo jerarquía en el trazado principalmente por su dimensión y por romper las formas preestablecidas de la trama. En este sentido, el punto tensor puede ser anterior o disponerse estipulando una dirección, que en cualquiera de los casos genera o marca actividades, usos o desarrollos (Figura 8).

Ante lo expuesto, la espacialidad distingue tanto el eje como los elementos edificatorios y libres, así como las sucesiones que siguen a estos y conforman agrupaciones o series que se repiten y entrelazan con otros elementos de comunicación que se interceptan y tejen. Este es el caso del camino a Antioquia y el de Istmina, del eje al aeropuerto, al Cementerio San José o el Antiguo Hospital, entre otros que, además de vías, se convierten en dispositivos generadores de espacialidades. Sin embargo, se precisa que no se trata solo del eje tensor, sino del espacio punto, esto es, de la espacialidad en sí misma, del elemento conformado y conformador y, por ende, cargado de significados. Así, se trata de la generación de espacialidades cargadas de valores históricos, estéticos y simbólicos, de significados y memorias colectivas, de simbologías y recuerdos asociados a los lugares y las espacialidades.

12 Para ampliar los análisis de estas zonas véase Rodríguez (2019). 


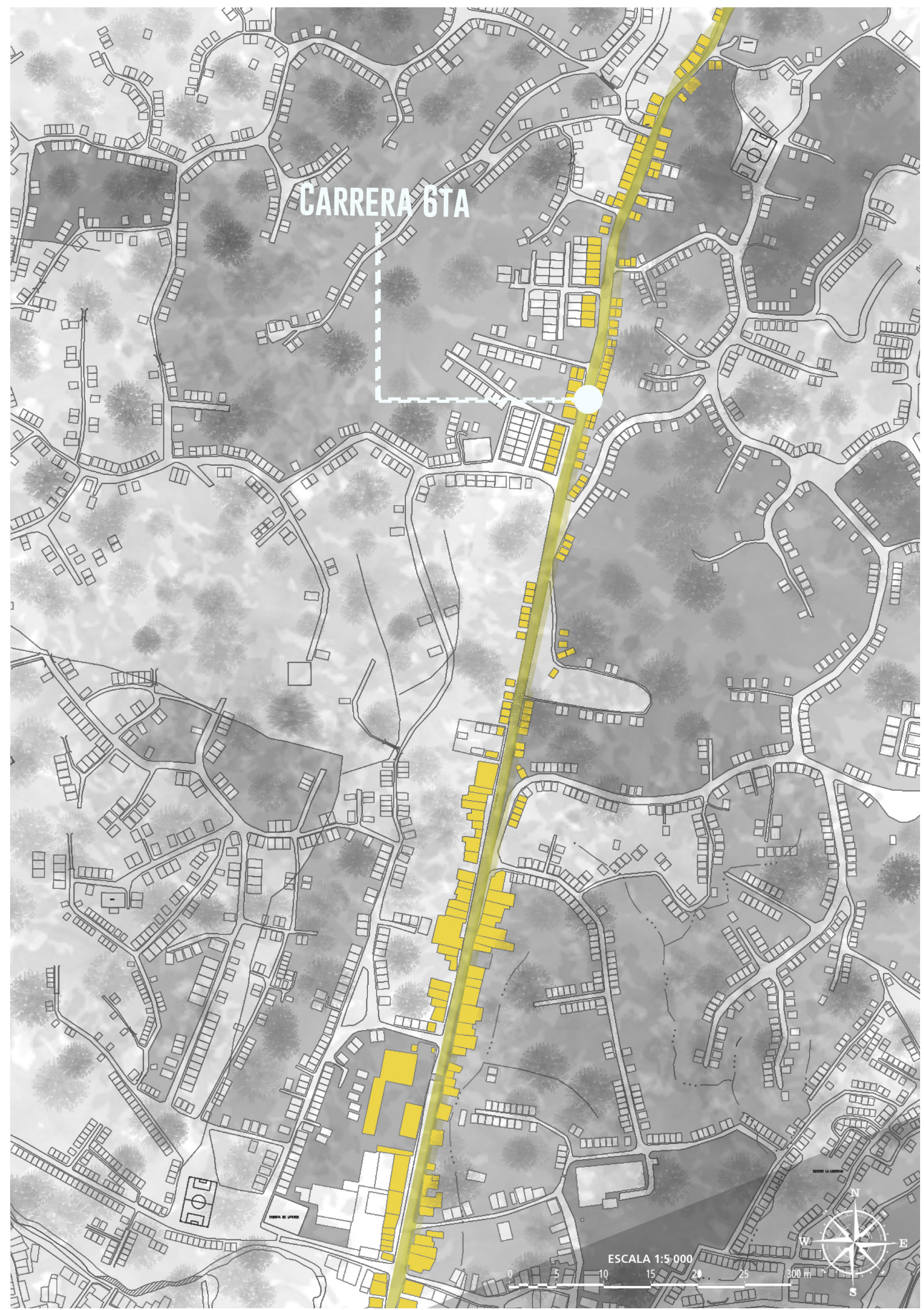

FIGURA 8. Configuración lineal articular: puntos tensores

FUENTE: análisis propio; representación gráfica: María Paula Malaver. 


\section{Reflexiones finales}

Las indagaciones realizadas en el trazado urbano de Quibdó desde una perspectiva que apuesta por la constitución del espacio, el territorio y el patrimonio en correlación con las comunidades locales evidencia que la traza de esta ciudad se soporta en diversas relaciones que se establecen con y desde el espacio físico y natural. Ahora, más allá de una ubicación espacial, la aproximación al trazado permite entender su constitución en correspondencia con hechos históricos y dinámicas económicas, sociales y culturales, pero también con formas de pensamiento, resistencias y luchas que los grupos humanos emprenden y materializan en este.

Así mismo, ilustra las relaciones que se tejen entre la sociedad y el espacio en diferentes ámbitos, como el regional, el territorial y el local, e incita a meditar redes, movimientos e imbricaciones posibles de rastrear en las territorializaciones que acontecen en el Pacífico. Cabe subrayar que la lectura del trazado de Quibdó revela la construcción social y cultural del espacio puntualizada en constituciones espaciales que evidencian saberes, conocimientos y apropiaciones vinculadas con las formas del saber y el hacer de los pobladores locales. En este sentido, posibilita la valoración que vislumbra patrimonio material e inmaterial, en la medida en que rastrea atributos, memorias, apropiaciones, simbologías, saberes y tradiciones de los pobladores que se tejen en las espacialidades y las configuraciones identificadas. De igual forma, permite entender los análisis espaciales en relación con la historia, la geografía y lo social, y de estos con el patrimonio.

Se subraya que las condiciones físicas, naturales y ambientales del entorno guardan estrecha relación con las maneras de habitar, con las lógicas y las prácticas, pero también con las formas de organización, ordenación y ubicación, las cuales - entretejidas con elementos culturales - evidencian la construcción de espacialidades en el tiempo. Ahora bien, la aproximación al trazado permite tejer hechos históricos, políti- cos, económicos, dinámicas sociales y culturales y rastrear formas de ordenamiento y funcionamiento, que en Quibdó se hallan vinculadas a las condiciones del lugar y generan adaptaciones, soluciones y constituciones. En síntesis, una aproximación que apuesta por promover lecturas que exploren la relación de la geografía, la historia, lo social, lo urbano y lo arquitectónico con las formas de valoración del patrimonio, que tejan entendimientos y constituciones locales que busquen promover abordajes patrimoniales diversos.

\section{Referencias}

Aprile-Gniset, J. (1993). Poblamiento, hábitats y pueblos del Pacífico. Editorial Univalle.

Capel, H. (2002). La morfología de las ciudades. Sociedad, cultura y paisaje urbano. Ediciones del Serbal.

Claval, P. (2002). El enfoque cultural y las concepciones geográficas del espacio. Boletín de la Asociación de Geógrafos Españoles, 34, 21-39.

Crespo, J. \& Vila, D. (2014). Saberes y conocimientos ancestrales, tradicionales y populares: el buen conocer y el diálogo de saberes dentro del proyecto buen conocer - Flok Society. https://floksociety.org/docs/Espanol/5/5.3.pdf

Deleuze, G. \& Guattari, F. (2000). Mil mesetas: capitalismo y esquizofrenia. Pretextos.

González, L. F. (2003). Quibdó: contexto histórico, desarrollo urbano y patrimonio arquitectónico. Universidad Nacional de Colombia.

Guzmán, D., Ruíz, J. F., \& Cadena, M. (2014). Regionalización de Colombia según la estacionalidad de la precipitación media mensual, a través análisis de componentes principales (ACP). Grupo de Modelamiento de Tiempo, Clima y Escenarios de Cambio Climático, Subdirección de Meteorología, IDEAM.

Hadad, G. \& Gómez, C. (2007). Territorio e identidad. Reflexiones sobre la construcción de territorialidad en los movimientos sociales latinoamericanos. IV Jornadas de Jóvenes Investigadores. Instituto de Investigaciones Gino Germani, Facultad de Ciencias Sociales, Universidad de Buenos Aires. https://www.aacademica.org/000-024/152

Haesbaert, R. (2011). El mito de la desterritorialización: del "fin de los territorios" a la multiterritorialidad. (Trad. Marcelo Canossa). Siglo xxi. 
Harvey, D. (1977). Urbanismo y desigualdad social. (Trad. Marina González). Siglo xxI.

Harvey, D. (2018). Fusticia, naturaleza y la geografia de la diferencia. Instituto de Altos Estudios Nacionales del Ecuador; Traficantes de Sueños.

Lee Alardín, M. G. (2016). Sobre el concepto de patrimonio urbano. Estudios sobre Conservación, Restauración y Museología, 3. https://www.revistas.inah.gob.mx/ index.php/estudiosconservacion/article/view/7741

Martínez, S. P. (2010). La política de titulación colectiva a las comunidades negras del Pacífico colombiano: una mirada desde los actores locales. Boletín de Antropología, 24(41), 13- 43.

Maseey, D. (2012). Espacio, lugar y política en la coyuntura actual. Urban, 4, 7-12.

Mosquera, G. (2010). Vivienda y arquitectura tradicional en el Pacífico colombiano, patrimonio cultural afrodescendiente. $\mathrm{Ca}^{-}$ talogación de tipologías arquitectónicas y urbanisticas propias de la región Pacífica colombiana. Universidad del Valle.

Prats, Ll. (1997). Antropología y patrimonio. Ariel.

Quintero, J. R., Ramírez, Y. A., \& Cortázar, A. M. (2020). Transporte fluvial en Colombia: operación, infraestructura, ambiente, normativa y potencial de desarrollo. Revista Ciudades, Estados y Política, 7(1), 4968. https://doi.org/10.15446/cep.v7n1.72778

Ramírez, B. R. \& López, L. (2015). Espacio, paisaje, región, territorio y lugar: la diversidad en el pensamiento contemporáneo. unAm, Instituto de Geografía; uam, Xochimilco.
Restrepo, E. (2016). Espacialidades afrodescendientes en el Pacífico colombiano. En: A. Liberac et al. (eds.), Territórios de gente Negra: processos, transformações e adaptações: ensaios sobre Colômbia e Brasil (pp. 189-213). EDUFRB.

Rodríguez, N. (2019). Patrimonios, espacios y territorios. Óptica de la experticia y prácticas locales en Quibdó (1880-1970). Universidad Javeriana.

Romero, J. (2009). Geografia económica del Pacifico colombiano. Serie Documentos de Trabajo Sobre Economía Regional y Urbana, no 116. Banco de la República.

Santos, M. (2000). La naturaleza del espacio. Técnica y tiempo, razón y emoción. Ariel.

Silva, D. (2016). Construcción de territorialidad desde las organizaciones campesinas en Colombia. Polis (Santiago), 15(43), 633-654. https://dx.doi.org/10.4067/ S0718-65682016000100029

Sorre, M. (1943). Les fondements de la géographie humaine: Essai d'une écologie de l'homme. Armand Colin.

Vargas, G. (2012). Espacio y territorio en el análisis geográfico. Reflexiones, 91(1), 313-326. https://www.redalyc. org/articulo.oa?id=72923937025

West, R. ([1957] 2000). Las tierras bajas del Pacífico colombiano. ICANH.

Zambrano, F. (2010). Estudio histórico. Plan Especial de Manejo y Protección (PEMP) del conjunto de inmuebles de arquitectura republicana y su zona de influencia en la ciudad de Quibdó, Departamento del Chocó. [Documento técnico de soporte. Volumen II. Diagnóstico del PEMP]. Unión Temporal PEMP. 